\title{
Inertial sensors as measurement tools of elbow range of motion in gerontology
}

This article was published in the following Dove Press journal:

Clinical Interventions in Aging

23 February 2015

Number of times this article has been viewed

\section{G Sacco ${ }^{1-3, *}$ \\ JM Turpin ${ }^{3,4, *}$ \\ A Marteu ${ }^{5}$ \\ C Sakarovitch ${ }^{6}$ \\ B Teboul ${ }^{2}$ \\ L Boscher ${ }^{4,5}$ \\ P Brocker ${ }^{4}$ \\ P Robert ${ }^{1-3}$ \\ O Guerin $2,3,7$}

'Memory Center, Claude Pompidou Institut, Department of Geriatrics, University Hospital of Nice, Nice, France; ${ }^{2}$ Centre d'Innovation et d'Usages en Santé (CIU-S), University Hospital of Nice, Cimiez Hospital, Nice, France; ${ }^{3} \mathrm{CoBTeK}$ Cognition Behaviour Technology EA 7276, Research Center Edmond and Lily Safra, Nice Sophia-

Antipolis University, Nice, France;

${ }^{4}$ Rehabilitation Unit, Department

of Geriatrics, University Hospital of Nice, Cimiez Hospital, Nice, France;

${ }^{5}$ Rehabilitation Unit, Department of Neurosciences, University Hospital of Nice, L'Archet Hospital, Nice, France; ${ }^{6}$ Department of Clinical Research and Innovation, University Hospital of Nice, Cimiez Hospital, Nice, France; ${ }^{7}$ Acute Geriatrics Unit, Department of Geriatrics, University Hospital of Nice, Cimiez Hospital, Nice, France

*These authors contributed equally to this work
Correspondence: G Sacco

Memory Center, Institut Claude Pompidou, Department of Geriatrics, University Hospital of Nice, 10 Rue Molière, 06100 Nice, France

Tel +33 609733254

Email sacco.g@chu-nice.fr
Background and purpose: Musculoskeletal system deterioration among the aging is a major reason for loss of autonomy and directly affects the quality of life of the elderly. Articular evaluation is part of physiotherapeutic assessment and helps in establishing a precise diagnosis and deciding appropriate therapy. Reference instruments are valid but not easy to use for some joints. The main goal of our study was to determine reliability and intertester reproducibility of the MP-BV, an inertial sensor (the MotionPod ${ }^{\circledR}[\mathrm{MP}]$ ) combined with specific software (BioVal $[\mathrm{BV}]$ ), for elbow passive range-of-motion measurements in geriatrics.

Methods: This open, monocentric, randomized study compared inertial sensor to inclinometer in patients hospitalized in an acute, post-acute, and long-term-care gerontology unit.

Results: Seventy-seven patients (mean age 83.5 \pm 6.4 years, sex ratio 1.08 [male/female]) were analyzed. The MP-BV was reliable for each of the three measurements (flexion, pronation, and supination) for $24.3 \%$ (CI 95\% 13.9-32.8) of the patients. Separately, the percentages of reliable measures were $59.7 \%(49.2-70.5)$ for flexion, $68.8 \%(58.4-79.5)$ for pronation, and $62.3 \%$ (51.2-73.1) for supination. The intraclass correlation coefficients were $0.15(0.07-0.73), 0.46$ (0.27-0.98), and $0.50(0.31-400.98)$ for flexion, pronation, and supination, respectively.

Conclusion: This study shows the convenience of the MP-BV in terms of ease of use and of export of measured data. However, this instrument seems less reliable and valuable compared to the reference instruments used to measure elbow range of motion in gerontology.

Keywords: reliability, intertester reproducibility, inclinometer

\section{Introduction}

Musculoskeletal system deterioration among the aging is a major reason for loss of autonomy and directly affects the quality of life of the elderly. ${ }^{1-3}$ In this context, physiotherapeutic assessment helps in evaluating elderly patient deficiencies and thus in planning an appropriate rehabilitation program. Articular evaluation is part of this assessment and allows joint deviation quantification, identification of orthopedic deformities, observation of painful events, and follow-up of progress made by patients. It also helps in establishing a precise diagnosis and deciding appropriate therapy. ${ }^{4}$

An essential stage of this evaluation is the measurement of joint angles. Within a clinical setting, physiotherapists do have technical references: the goniometer and inclinometer are valid instruments, ${ }^{5-7}$ however, positioning of these tools is not easy with some joints. ${ }^{8-10}$ Other techniques are also used in tests: the meter ribbon (easy use for estimating improvement in range of motion [ROM] but not adapted to a unique assessment) and visual assessment (often practiced in clinical tests but subjective and not entirely replicable). ${ }^{11,12}$ It seemed necessary to find an instrument that would allow a combination of all the assets of those reference techniques - that is, an instrument that is reliable and replicable but also simple, fast, and easy to use. 
Actigraphy is a technique for measuring locomotive activity. Traditionally, actimeters were composed of single piezoelectric accelerometers worn on the waist. ${ }^{13}$ With the improvement of technology in the past 30 years, actimeters have become more precise (with multiple piezoelectric accelerometers) and the position of wear has been diversified (wrist, chest, hip) in response to new applications. ${ }^{14}$ Several practical applications of actigraphy have been proposed, such as assessment of hyperactivity in children ${ }^{15,16}$ and behavioral disorders among patients suffering from dementia; ${ }^{17,18}$ ecological assessment of daily living activities; ${ }^{19}$ assessment of sedative effects of some drugs; ${ }^{20}$ and screening for certain sleep problems. ${ }^{21-23}$ However, the actigraph can also be used for measurement of articular ROM. Indeed, the actigraph, in combination with specific software, is used as an inertial sensor for measurement of lower limb articulations ${ }^{24-27}$ but also for cervical spine. ${ }^{28}$

The main goal of the present study was to determine reliability, with an inclinometer as reference, and intertester reproducibility of an actigraph that uses an inertial sensor (the MotionPod ${ }^{\circledR}$; Movea SA, Grenoble, France) associated with specific software (BioVal; RM Ingénieurie, Groupe Cegedim, Rodez, France) for obtaining elbow passive ROM measurements in geriatrics. In this study, we also evaluated the duration of examination and the acceptability of the instrument according to the patient and the physiotherapist. From this point onward, we shall use the term "MP-BV" to define the actigraph/software coupling.

\section{Methods}

\section{Location and subjects}

This open, monocentric, randomized study (NCT01462760) took place from October 1, 2011 to May 1, 2012. Patients were recruited within the acute, post-acute, and long-termcare gerontology unit of University Hospital of Nice (Nice, France). The study was approved by the South Mediterranean V Ethical Review Board (Comité de Protection des Personnes Sud Méditérrannée V), as well as by the French Agency for the Safety of Health Products (ANSM). Patients who agreed to participate gave their written informed consent.

Included patients were 65 years or older and had received a physiotherapy prescription from the physiotherapists of Department of Geriatrics mentioning the need for a passive joint assessment. Patients who agreed to participate had to be covered by social insurance. Exclusion criteria were: patients suffering from a pathology for which heating of joints was contraindicated; patients wearing a pacemaker, a metallic prosthesis, or osteosynthesis equipment located less than $10 \mathrm{~cm}$ from the captor; patients incapable of maintaining a straight wrist position and/or a neutral shoulder position; and patients having a joint deviation in flexion, extension, pronation or supination of less than $20^{\circ}$.

\section{Recruitment and randomization}

Patients were pre-recruited during weekly physiotherapy sessions at the Department of Geriatrics. Due to organizational constraints, a maximum of six patients per week were included. An explanation of the study and an associated pamphlet were given to the patients by the physician responsible for the study, with a 7-day retraction delay. The inclusion visit began with signing of consent and was led by the physician after those 7 days.

At the end of the inclusion visit, an inclusion form was completed by the physician. This form included the first and last name of the patient and the confirmation of all inclusion and non-inclusion criteria. Then, this form was forwarded to a clinical research assistant of the Clinical Research and Innovation Department (DRCI), who randomly assigned the patients. The randomization was centralized at the methodological center and done in a 1:1 ratio. The generation of the allocation sequence was made with number permutation tables in block sizes of six. Consequently, among six patients, three were allocated to room A and three were allocated to room B, and so on. All patients were examined successively in both rooms. Furthermore, in room A, the running order on both instruments (MP-BV and inclinimeter) was also randomized. Physiotherapists were also randomly assigned to room A or B (Figure 1).

\section{Materials used for the measures}

The MotionPod is a patented hardware solution for motion sensing that features a state-of-the-art miniaturized motion-sensing microelectromechanical system. It contains three-axis accelerometers, three-axis magnetometers, and three-axis gyroscopes in a compelling form factor the size of a standard wristwatch $\left(33 \times 21 \times 15 \mathrm{~mm}\left[1.3 \times 0.8 \times 0.6^{\prime \prime}\right]\right)$ and weighs $14 \mathrm{~g}(0.5 \mathrm{oz})$. The battery was a $150 \mathrm{mAh} \mathrm{Li}$-ion polymer technology battery with a battery life of 6 hours and a charging duration of $2-3$ hours ( 500 charging cycles). The device is worn by a patient by way of a bracelet attached to the mechanical interface. The sampling rate for accelerometers, gyroscopes, and magnetometers was adjustable between 25 and $200 \mathrm{~Hz}$ with 12-bit resolution. The information from the MotionPod was transferred via radio waves to the MotionPod controller, which was linked to a computer with a USB cable. The wireless band ranged from $10 \mathrm{~m}$ (30 feet) to $30 \mathrm{~m}$ (100 feet), depending on the environment, with a frequency band of $2.4 \mathrm{Ghz}$. The measurement range was a full $360^{\circ}$. The fusion of data from accelerometers, magnetometers, and gyroscopes was done with an application programming 


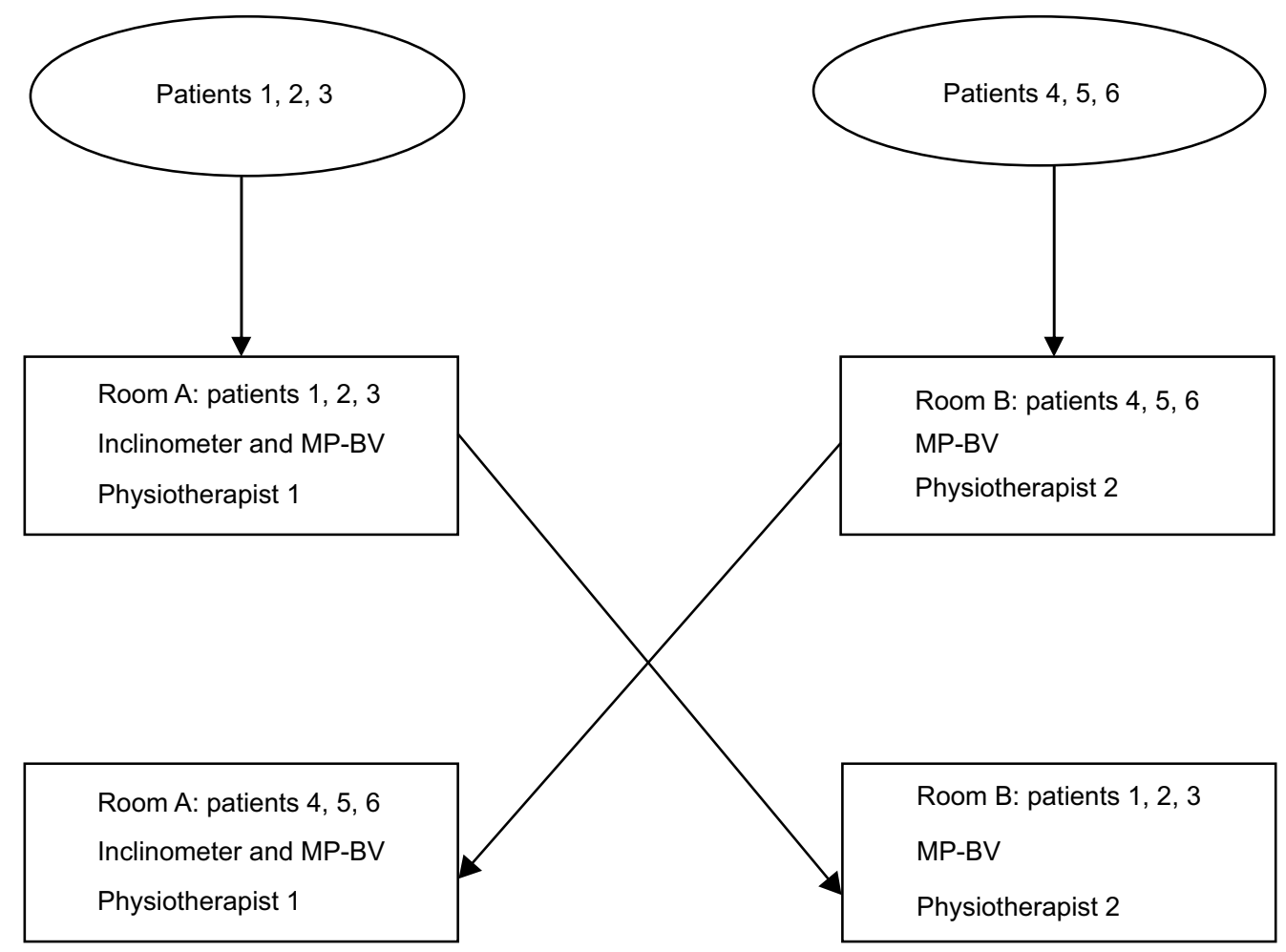

Figure I Randomization process.

Abbreviation: MP-BV, MotionPod ${ }^{\circledR}$ inertial sensor associated with BioVal software.

interface developed by Movea. Then, data were delivered by the BioVal software to the practitioner as yaw, pitch, roll, quaternion, or rotation matrix. The resolution was $0.5^{\circ}$ for static accuracy and $1^{\circ}$ for dynamic accuracy.

The inclinometer used as reference was the Baseline ${ }^{\circledR}$ Bubble inclinometer (Fabrication Enterprises, Withe Plains, NY, USA), the dimensions of which were $101.6 \times 5.08 \times 101.6 \mathrm{~mm}\left(4 \times 0.2 \times 4^{\prime \prime}\right)$ for $90.72 \mathrm{~g}(0.2 \mathrm{lbs})$. For the measure, the inclinometer was placed near the elbow. The physiotherapist turned the dial until the scale read 0 , then took the elbow through its range of motion. Finally, the range was read directly from the dial.

\section{Experimentation process}

Experimentation was performed in the Physiotherapy Unit of the Gerontology Department over one half-day per week. A training session on both instruments used in this study was held by physiotherapists before the study began so that all four investigators had the same level of knowledge regarding the use of the MP-BV. No physiotherapist had had any experience with any inertial sensor before the training sessions.

Measurements were made on the elbow joint, as it allows good validity and intertester reproducibility. ${ }^{5}$ Physiotherapists successively measured flexion, pronation, and supination. In room A, experimentation included measurement with the MP-BV as well as with the inclinometer. The screen displaying the result was hidden from the physiotherapist so as not to influence the inclinometer measurement. In room B, the experiment included a measurement with the MP-BV, in order to assess intertester reliability. Considering that inclinometer was the instrument of reference, only one measure was taken. For MP-BV two measures were taken for each patient to assess intertester reliability, which were performed by different physiotherapists for each measure.

When the passive elbow flexion was measured, the arm was placed vertically and the forearm was placed in supination in the same straight line as that formed by the arm. The inclinometer was placed on the longitudinal axis of the mobile segment, on the dorsal surface, and on the middle of the forearm. For this measurement, we used two MotionPod devices; the first one, fixed on the wrist, measured the joint angle, and the second one, on the arm, was used as reference positioning (Figure 2).

Regarding pronosupination, the arm was placed vertically; the forearm was placed horizontally with the palm of the hand up, the thumb upward, and the longitudinal axis of the third metacarpus in the same axis as the forearm. The inclinometer was positioned on the dorsal face of the wrist and the MotionPod the motion pod was positioned on the external face of the wrist. 


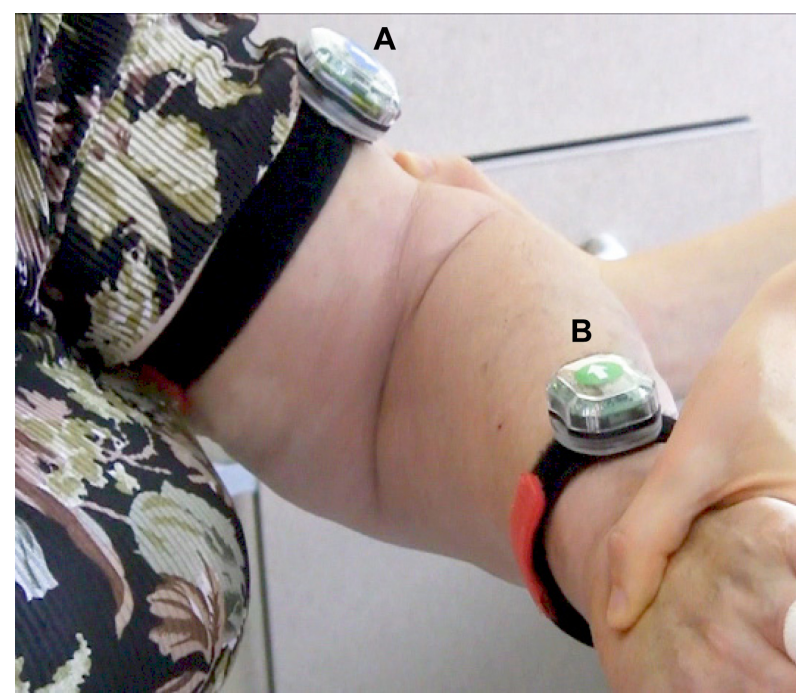

Figure 2 Positioning of the actimeters.

Notes: (A) Actimeter reference positioning. (B) Actimeter measuring elbow range of motion.

\section{Variables studied}

\section{Measurement reliability}

Passive elbow ROM measurements expressed in degrees and obtained with the MP-BV were compared to those obtained with an inclinometer for all three of the movements (flexion, pronation, and supination). We excluded elbow extension because the articular deviation of this joint is inferior to $10^{\circ}$, which is inferior to the variability accepted between the two techniques. A $10^{\circ}$ scope of error is acceptable for goniometric measurements. ${ }^{29}$ Consequently, we considered as reliable a measure with the MP-BV with a difference of less than $10^{\circ}$ of the measure obtained with the inclinometer. The percentage of reliable measure was calculated in this way for each movement.

\section{Intertester reproducibility}

Intertester reproducibility was assessed through two series of passive ROM measurements conducted with the MP-BV by two researchers. For each of the three movements, intertester reproducibility of MP-BV measurement was evaluated by calculating the intraclass correlation coefficient (ICC). ${ }^{30}$ Reproducibility was also evaluated through the rates of concordant measures with both techniques (less than $10^{\circ}$ difference between the measures) for each movement.

\section{Duration of examination}

The durations of examination (in seconds) obtained with both instruments were compared. Duration was defined as the time at which the patient was ready for examination until the time at which the data were recorded in the patient's file.

\section{Acceptability}

The patient rated the comfort of the measurement process for both instruments using a ten-point visual analog scale (VAS). Meanwhile, each physiotherapist rated his acceptance of the instruments using a 10-point VAS, as well as the ease of use and of data exporting of both instruments.

\section{Statistical analysis}

It was decided a priori that MP-BV would be considered a reliable measurement technique if the three joint angles from at least $90 \%$ of patients had less than $10^{\circ}$ error when compared to the inclinometer. Considering the assumption that $95 \%$ of patients would have a valid measure, it was necessary to include 73 patients so that the lower limit of the $95 \%$ confidence interval (CI) would be above $90 \%$. To account for potential measurement failures, the decision was made to include 84 patients.

First, a descriptive analysis was made by the biostatistician from the DRCI of Nice University Hospital. Results were presented as mean \pm standard deviation for quantitative variables and percentage for qualitative variables. The percentage of patients with a valid global assessment was calculated and presented with the corresponding 95\% CI as well as percentages of reliable measurements for each movement (flexion, pronation, supination). An ICC value $<0.40$ was considered poor, $0.40-0.50$ moderate, $0.50-0.70$ good, and $0.70-1.0$ excellent. ${ }^{31}$ Examination duration was compared between the two techniques using the Student's $t$-test for paired data. For this analysis, only data recorded in room A were used, as examinations were performed there with both techniques and by the same physiotherapist. Finally, for acceptability analyses, VAS scores (recorded in room A) were compared using the Student's $t$-test for paired data. All the tests were two-sided and the significance level was set to $5 \%$. Statistical analyses were performed using SAS Enterprise Guide (v 4.1; SAS Institute Inc., Cary, NC, USA).

\section{Results}

Three hundred and fifteen patients were screened during weekly physiotherapy sessions. Of these, 84 patients were deemed eligible for inclusion in the study, and 77 of these $84(91.7 \%)$ were eventually included in the validation study (Figure 3).

Characteristics of the patients with missing data for analyses did not differ significantly from analyzable patients. For these 77 patients, the mean age was $83.5 \pm 6.4$ (range 68-101) years; $40(52.0 \%)$ were women and $37(48.0 \%)$ men, resulting in a sex ratio of 1.08 . 


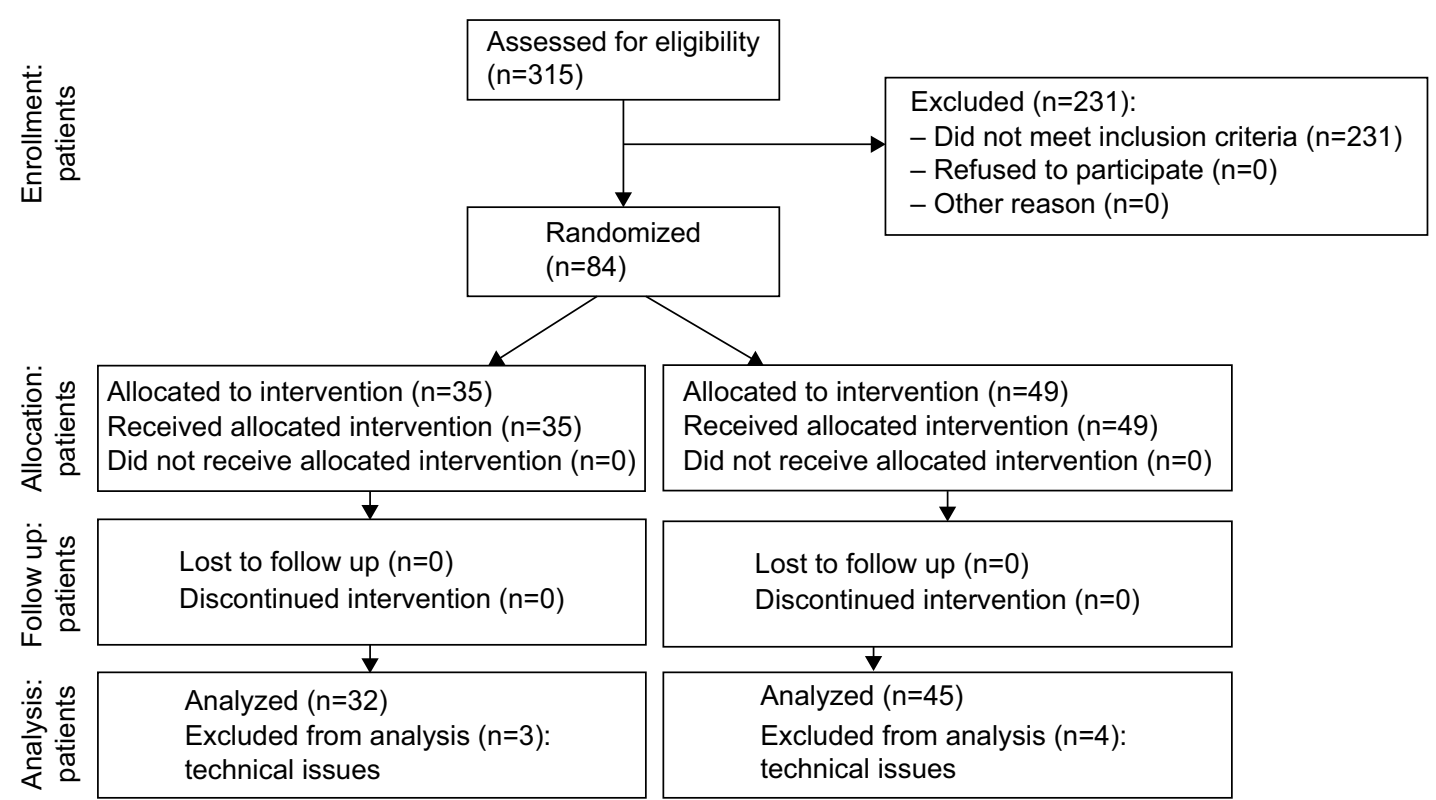

Figure 3 Consort flow diagram.

\section{Measuring reliability}

The MP-BV was reliable on each of the three measurements (flexion, pronation, and supination) for $24.3 \%$ (13.9-32.8) of the patients. Separately, the percentages of reliable measures were $59.7 \%$ (49.2-70.5) for flexion, 68.8\% (58.4-79.5) for pronation, and $62.3 \%$ (51.2-73.1) for supination (Table 1).

\section{Intertester reproducibility}

The ICCs were $0.15(0.07-0.73)$ for flexion, $0.46(0.27-0.98)$ for pronation, and $0.50(0.31-0.98)$ for supination. For the same movements, respectively, the concordant measures percentages were $53.2 \%$ (42.1-64.4), 57.1\% (46.1-68.2), and $53.2 \%(42.1-64.4)$.

\section{Duration of examination}

Mean examination duration was significantly longer with the MP-BV than with the inclinometer, at $117.4( \pm 26.9)$ seconds and $104.4( \pm 34.0)$ seconds, respectively $(P<0.0001)$.

\section{Acceptability}

There was no significant difference between the two instruments regarding patient comfort, with a mean VAS score for the MP-BV of $9.21( \pm 1.10)$ versus $9.26( \pm 0.99)$ for the inclinometer $(P=0.49, \mathrm{DF}=76, t=0.69)$. Results were the same regarding the physiotherapist's acceptance of the instruments, with a mean VAS score of $7.88( \pm 1.97)$ for the MP-BV and $7.70( \pm 1.70)$ for the inclinometer $(P>0.05, \mathrm{DF}=76, t=1.43)$.

Regarding the ease of use, the mean VAS score was $8.55( \pm 1.21)$ for the MP-BV versus $7.13( \pm 2.54)$ for the inclinometer $(P<0.0001, \mathrm{DF}=76, t=6.07)$. Results were similar regarding the data exportation, with a mean VAS score of $8.76( \pm 1.44)$ for the MP-BV and $7.24( \pm 2.7)$ for the inclinometer $(P<0.0001, \mathrm{DF}=76, t=4.75)$.

\section{Adverse events}

No adverse events were recorded during the study.

\section{Discussion}

Measuring articular ROM requires the use of various instruments. However, even those instruments provide reliable and replicable measures, they present difficulties in the use and the use of reference instruments (like inclinometer or goniometer) required that the user was very rigorous in positioning the instrument before using it. ${ }^{10}$ The purpose of this study was

Table I Proportion of valid measures for each movement

\begin{tabular}{lllll}
\hline $\begin{array}{l}\text { Movement, } \\
\text { N=77 }\end{array}$ & $\begin{array}{l}\text { MP-BV, } \\
\text { mean } \pm \text { SD }\end{array}$ & $\begin{array}{l}\text { Inclinometer, } \\
\text { mean } \pm \text { SD }\end{array}$ & $\begin{array}{l}\text { Difference in absolute value between the } \\
\text { MP-BV and the inclinometer, mean } \pm \text { SD }\end{array}$ & Proportion of valid measures (95\% CI) \\
\hline Flexion & $147.1 \pm 27.7$ & $155.3 \pm 11.4$ & $14.8 \pm 25.2$ & $59.74 \%(0.4879 ; 0.7069)$ \\
Pronation & $94.6 \pm 15.5$ & $91.8 \pm 12.2$ & $8.1 \pm 6.9$ & $68.83 \%(0.5849 ; 0.7918)$ \\
Supination & $72.3 \pm 14.4$ & $78.8 \pm 11.6$ & $10.9 \pm 8.9$ & $62.34 \%(0.5152 ; 0.7316)$ \\
\hline
\end{tabular}

Note: Data is measured in degrees.

Abbreviations: $\mathrm{Cl}$, confidence interval; MP-BV, MotionPod ${ }^{\circledR}$ inertial sensor associated with BioVal software; SD, standard deviation. 
to determine the reliability and the intertester reproducibility of the MP-BV as a new measurement instrument for ROM, which may be simpler to use than other instruments.

The results of this study show the convenience of the MP-BV in terms of ease of use and of export of measured data. However, this instrument seems less reliable and useful compared to the reference instruments used to measure elbow ROM in gerontology.

The choice of measurement instrument in clinical practice is not consensual, and study results differ between authors. ${ }^{8,32}$ For this reason, van de Pol et $\mathrm{al}^{33}$ concluded in their literature review that more research regarding these instruments was necessary. In our study, we chose the inclinometer as a reference instrument due to its validity, but also because of its higher intertester reproducibility compared to a classical goniometer on the elbow joint. ${ }^{34}$ Moreover, the inclinometer is a fast and easy-to-use instrument with which physiotherapists from the Nice University Hospital are familiar. Finally, an important physiological valgus could hamper common goniometer implementation on the elbow joint. Chapleau et $\mathrm{al}^{29}$ highlighted in their study the need for using radiological measurement in clinical protocols. However, radiological measurement was difficult to apply in our study.

Remarkably, this study analyzed 77 patients, which represents a significant number of patients compared to similar studies which have validated reference instruments. ${ }^{5,11}$ Within the context of the study, a double-blind experiment for measurements was not achievable.

We experienced some difficulties in measurement that could explain the differences between the two instruments' outcomes. Elbow flexion measurement is usually done by placing the shoulder in a neutral position, and the choice of using two inertial sensors was made to avoid subject compensation while performing this measure (shoulder protraction). Unlike the inclinometer, the MP-BV was attached to the skin; however, skin elasticity decreases with age, ${ }^{35,36}$ and, as a result, there was a low adjustment of the sensor in regard to the underlying bony landmark, creating a measurement difference higher than $10^{\circ}$. This particularity could also explain measurement differences when pronation and supination movements were performed.

Contrary to what was expected, the importance of a rigorous marked of reference point proved to be extremely important. Indeed, the positioning of the sensor on the joint by both physiotherapists was not exactly the same and may have been responsible for the different outcomes. Moreover, a clamping system was not provided with the MotionPod, and it was necessary to use a skin guard to protect the elderly patients' skin, which is often fragile, increasing tracking difficulties.

Regarding examination duration, it is important to note that this not only included examination duration, but also the setting-up of the skin guard, thus increasing the total measuring time with the MP-BV compared to the inclinometer.

\section{Conclusion}

With the continuing development of new technologies, we shall witness more and more new instruments that will require assessment using similar protocols to those used for medications. Based on this study, the MP-BV seems less reliable and to give less reproducible measures than one of the reference instruments used to assess elbow ROM in the elderly. Taking into account its limitations as well as its ease of both use and data exportation, it could be interesting to compare MP-BV measurements to radiographic measurements in a younger population.

\section{Acknowledgments}

The authors wish to thank Eric Fontas for his methodological support and Mathilde Demory for reviewing the English. We thank Marie Geronimi from RM Ingénieurie and Yanis Caritus from MOVEA for the technical informations. We also wish to thank the physiotherapists from the Gerontology Department (Damian Argini, Urko Larranaga, and Jérôme Danfali) and the rehabilitation health care manager Valérie Victor, as well as Professor Alain Franco and $\mathrm{Mr}$ Patrick Malléa.

\section{Author contributions}

All authors contributed toward data analysis, drafting and revising the paper and agree to be accountable for all aspects of the work.

\section{Disclosure}

This study benefited from Ministry of Industry funding within the Centre for Innovation and Health Usage (Centre d'Innovation et d'Usage en Santé [CIU-S]). MP-BV developers were part of the initial CIU-S project consortium. The statistical outcomes analysis was independently realized by the DRCI and the data interpretation was performed by physicians from the public hospital. Participants for this study (physicians, physiotherapists) who were involved in this research protocol and in the interpretation of the outcomes did not receive any specific compensation. The authors report no other conflicts of interest in this work. 


\section{References}

1. Callahan LF, Rao J, Boutaugh M. Arthritis and women's health: prevalence, impact, and prevention. Am J Prev Med. 1996;12(5):401-409.

2. Kelsey JL, White AA 3rd, Pastides H, Bisbee GE Jr. The impact of musculoskeletal disorders on the population of the United States. J Bone Joint Surg Am. 1979;61(7):959-964.

3. Janssen I, Heymsfield SB, Ross R. Low relative skeletal muscle mass (sarcopenia) in older persons is associated with functional impairment and physical disability. J Am Geriatr Soc. 2002;50(5):889-896.

4. Kolber MJ, Hanney WJ. The reliability and concurrent validity of shoulder mobility measurements using a digital inclinometer and goniometer: a technical report. Int J Sports Phys Ther. 2012;7(3):306-313.

5. Gogia PP, Braatz JH, Rose SJ, Norton BJ. Reliability and validity of goniometric measurements at the knee. Phys Ther. 1987;67(2): 192-195.

6. Bovens AM, van Baak MA, Vrencken JG, Wijnen JA, Verstappen FT. Variability and reliability of joint measurements. Am J Sports Med. 1990; 18(1):58-63.

7. Poichotte E. Inclinomètre et standardisation des mesures d'amplitude articulaire [Inclinometer and standardization of range of motion measurements]. Kinésithérapie Scientifique. 2005;460:37-43. French.

8. Armstrong AD, MacDermid JC, Chinchalkar S, Stevens RS, King GJ. Reliability of range-of-motion measurement in the elbow and forearm. J Shoulder Elbow Surg. 1998;7(6):573-580.

9. Gajdosik RL, Bohannon RW. Clinical measurement of range of motion. Review of goniometry emphasizing reliability and validity. Phys Ther. 1987;67(12):1867-1872.

10. Fish DR, Wingate L. Sources of goniometric error at the elbow. Phys Ther. 1985;65(11):1666-1670.

11. Watkins MA, Riddle DL, Lamb RL, Personius WJ. Reliability of goniometric measurements and visual estimates of knee range of motion obtained in a clinical setting. Phys Ther. 1991;71(2):90-96.

12. Bruton A, Ellis B, Goddard J. Comparison of visual estimation and goniometry for assessment of metacarpophalangeal joint angle. Physiotherapy. 1999;85(4):201-208.

13. Montoye HJ, Washburn R, Servais S, Ertl A, Webster JG, Nagle FJ. Estimation of energy expenditure by a portable accelerometer. $\mathrm{Med} \mathrm{Sci}$ Sports Exerc. 1983;15(5):403-407.

14. Chen KY, Bassett DR Jr. The technology of accelerometry-based activity monitors: current and future. Med Sci Sports Exerc. 2005;37(11 Suppl): S490-S500.

15. Dane AV, Schachar RJ, Tannock R. Does actigraphy differentiate ADHD subtypes in a clinical research setting? J Am Acad Child Adolesc Psychiatry. 2000;39(6):752-760.

16. Wiggs L, Montgomery P, Stores G. Actigraphic and parent reports of sleep patterns and sleep disorders in children with subtypes of attentiondeficit hyperactivity disorder. Sleep. 2005;28(11):1437-1445.

17. Nagels G, Engelborghs S, Vloeberghs E, Van Dam D, Pickut BA, De Deyn PP. Actigraphic measurement of agitated behaviour in dementia. Int J Geriatr Psychiatry. 2006;21(4):388-393.

18. Nagels G, Engelborghs S, Vloeberghs E, Lemmens W, Pickut BA, De Deyn PP. Correlation between actigraphy and nurses' observation of activity in dementia. Int J Geriatr Psychiatry. 2007;22(1):84-86.
19. Sacco G, Joumier V, Darmon N, et al. Detection of activities of daily living impairment in Alzheimer's disease and mild cognitive impairment using information and communication technology. Clin Interv Aging. 2012;7:539-549.

20. Stanley N. Actigraphy in human psychopharmacology: a review. Hum Psychopharmacol. 2003;18(1):39-49.

21. Brooks JO 3rd, Friedman L, Bliwise DL, Yesavage JA. Use of the wrist actigraph to study insomnia in older adults. Sleep. 1993;16(2): 151-155.

22. Yesavage JA, Friedman L, Kraemer HC, et al. A follow-up study of actigraphic measures in home-residing Alzheimer's disease patients. J Geriatr Psychiatry Neurol. 1998;11(1):7-10.

23. Friedman L, Benson K, Noda A, et al. An actigraphic comparison of sleep restriction and sleep hygiene treatments for insomnia in older adults. J Geriatr Psychiatry Neurol. 2000;13(1):17-27.

24. Zhang JT, Novak AC, Brouwer B, Li Q. Concurrent validation of Xsens MVN measurement of lower limb joint angular kinematics. Physiol Meas. 2013;34(8):N63-N69.

25. Watanabe T, Saito H. Tests of wireless wearable sensor system in joint angle measurement of lower limbs. Conf Proc IEEE Eng Med Biol Soc. 2011;2011:5469-5472.

26. Watanabe T, Saito H, Koike E, Nitta K. A preliminary test of measurement of joint angles and stride length with wireless inertial sensors for wearable gait evaluation system. Comput Intell Neurosci. 2011; 2011:975193.

27. Cooper G, Sheret I, McMillan L, et al. Inertial sensor-based knee flexion/ extension angle estimation. J Biomech. 2009;42(16):2678-2685.

28. Theobald PS, Jones MD, Williams JM. Do inertial sensors represent a viable method to reliably measure cervical spine range of motion? Man Ther. 2012;17(1):92-96.

29. Chapleau J, Canet F, Petit Y, Laflamme GY, Rouleau DM. Validity of goniometric elbow measurements: comparative study with a radiographic method. Clin Orthop Relat Res. 2011;469(11):3134-3140.

30. Lin L, Hedayat AS, Sinha B, Yang M. Statistical methods in assessing agreement: models, issues, and tools. J Am Stat Assoc. 2002;97(457): 257-270.

31. Fleiss JL. The Design and Analysis of Clinical Experiments. New York, NY: John Wiley \& Sons; 1986.

32. Goodwin J, Clark C, Deakes J, Burdon D, Lawrence C. Clinical methods of goniometry: a comparative study. Disabil Rehabil. 1992;14(1): $10-15$.

33. van de Pol RJ, van Trijffel E, Lucas C. Inter-rater reliability for measurement of passive physiological range of motion of upper extremity joints is better if instruments are used: a systematic review. J Physiother. 2010;56(1):7-17.

34. Petherick M, Rheault W, Kimble S, Lechner C, Senear V. Concurrent validity and intertester reliability of universal and fluid-based goniometers for active elbow range of motion. Phys Ther. 1988;68(6):966-969.

35. Firooz A, Sadr B, Babakoohi S, et al. Variation of biophysical parameters of the skin with age, gender, and body region. Scientific World Journal. 2012;2012:386936.

36. Levakov A, Vucković N, Dolai M, Kaćanski MM, Bozanić S. Agerelated skin changes. Med Pregl. 2012;65(5-6):191-195.
Clinical Interventions in Aging

\section{Publish your work in this journal}

Clinical Interventions in Aging is an international, peer-reviewed journal focusing on evidence-based reports on the value or lack thereof of treatments intended to prevent or delay the onset of maladaptive correlates of aging in human beings. This journal is indexed on PubMed Central, MedLine,

\section{Dovepress}

CAS, Scopus and the Elsevier Bibliographic databases. The manuscript management system is completely online and includes a very quick and fair peer-review system, which is all easy to use. Visit http://www.dovepress. com/testimonials.php to read real quotes from published authors. 